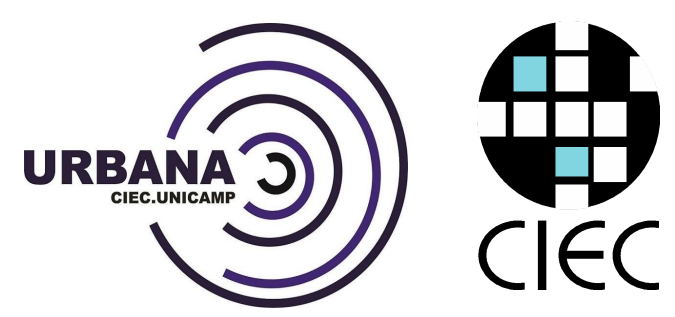

URBANA: Revista Eletrônica do Centro Interdisciplinar de Estudos sobre a Cidade Maria Emília Regina; Erica de Sousa Checcucci

arqmilaregina@gmail.com; erica_checcucci@hotmail.com | Universidade Federal da Bahia

\title{
Cenário de festas de largo em Salvador:
}

Da expressão cultural à padronização

Scenarios of "festas de largo" in Salvador:

From cultural expression to standardization

Escenario de "festas de largo" en Salvador:

De la expresión cultural a la normalización

\section{Introdução}

Dentre as diferentes expressões artísticas que marcam as Festas de Largo de Salvador, como a dança, a gastronomia e os jogos, é na arte de construir as barracas de venda de comida e bebida que este trabalho se centra, ou melhor, na perda da expressão artística destas barracas ao longo dos anos, apontando para a importância do resgate dessa produção artística cultural que compunha o cenário das Festas de Largo, haja visto a pobreza do cenário das festas atualmente. 
A história das Festas de Largo e, consequentemente, de suas barracas de venda de comida e bebida, está marcada por ações de diferentes ordens como a social, a econômica, a cultural, a governamental, dentre outras, que modificam seu aspecto e força ao longo do tempo na cidade. No caso das barracas percebe-se que elas entraram em um processo de padronização que minou as expressões artísticas evocadas historicamente nas festas.

As Festas de Largo em Salvador são manifestações tradicionais e marcantes. No portal da cidade (SALVADOR, 2020) são relacionadas 15 festas populares que acontecem ao longo do ano, além dos chamados "Ensaios de Verão". São elas: Festa de Santa Bárbara; Nossa Senhora da Conceição da Praia; Festa de Santa Luzia; Festival Virada Salvador; Festa de Boa Viagem e Bom Jesus dos Navegantes; Festa de Reis; Lavagem do Bonfim; São Lázaro; "Segunda-Feira Gorda" da Ribeira; Festa de Yemanjá; Lavagem de Itapuã; Fuzuê / Pré Carnaval de Salvador; Furdunço / Pré Carnaval de Salvador; Pipoco E Carnaval de Salvador.

Nossa Senhora da Conceição é a padroeira do Estado da Bahia e a festa da Conceição da Praia é considerada uma das mais antigas festas de Largo da Bahia (CASTRO JUNIOR, 2014). Ela acontece no Largo da Basílica da Conceição da Praia, na Cidade Baixa de Salvador todo o dia 08 de dezembro, precedida de um novenário que começa no dia 29 de novembro. De acordo com o calendário atual das festas baianas, a festa da Conceição é uma das primeiras do período de final e início de ano, e faz parte das "festas de verão" como são atualmente conhecidas.

De acordo com Brandão (1989, p. 8), a festa é: “[...] uma fala, uma memória e uma mensagem um lugar simbólico onde, cerimonialmente, separa-se o que deve ser esquecido [...] e aquilo que deve ser resgatado, posto em evidência de tempos em tempos".

Para Sant'Anna (2013, s/p.), as festas populares de rua, ou as "celebrações coletivas" como as chama, têm potencial simbólico incomensurável, pois, “[...] religiosas ou não, as celebrações coletivas 
são poderosos "marcadores" de espaços e instituidores de lugares e territórios aos quais memórias, sentimentos de identidade e de pertencimento estão associados".

As festas subvertem a ordem do dia a dia dos espaços públicos. Carvalho (2016, p. 8) destaca “[...] o compromisso que a festa tem com o próprio espaço [...] a festa é um rito transfigurador de apropriação da cidade de Salvador".

As intervenções municipais através de regulamentações publicadas ao longo dos anos, aqui tratadas como eventos, produziram alterações e condicionaram as Festas de Largo da cidade de Salvador.

A partir de meados da década de 90 do século XX as intervenções do Estado aparecem incisivas sobre a dinâmica e o cenário das festas e elas acabam por modificar o aspecto físico das barracas de venda de comida e bebida, com respeito à materialidade, dimensões, quantidade e estética.

Considerando que a partir de 1989 foi criado o Conselho Municipal de Festas Populares de Salvador, este trabalho se desenvolve a partir deste marco até os dias atuais, centrando-se na identificação e análise das leis estabelecidas pela municipalidade e destinadas a regulamentação das festas populares até o ano de 2018.

A partir deste trabalho, foi possível verificar como as barracas tradicionais das festas passaram de uma produção artesanal, artística e cultural para um sistema industrializado e utilitário. Foi possível também catalogar as barracas com vistas à preservação da sua memória e identificar possibilidades de atualização no seu sistema produtivo.

\section{As Festas enquanto Sistemas Dinâmicos Instáveis}

Sistemas Dinâmicos Instáveis são sistemas complexos compostos por diferentes elementos que interagem entre si. Segundo Nussenzveiog (2003), os sistemas complexos possuem as seguintes características: (a) estão em constante evolução, formando 
um grande número de unidades; (b) o sistema é aberto interagindo com o meio ambiente e cada unidade interage com um certo número menor de outras unidades; (c) o sistema é não-linear e cada unidade produz uma resposta aos sinais que recebe das outras, o estímulo recebido pode ser excitatório ou inibitório; (d) frustação, os sinais recebidos de unidades diferentes podem ser contraditórios, não satisfaz a todos ao mesmo tempo; (e) aprendizado, o sistema é adaptativo em função da experiência adquirida pela interação com o meio ambiente; $(f)$ aleatoreidade, algumas características do sistema são distribuídas ao acaso; (g) o sistema se auto-organiza de forma espontânea, criando ordem a partir de um estado desordenado; e (h) o sistema é hierárquico.

Ilyia Prigogine (2002) também trata as questões de instabilidade, entendendo esse substantivo como um dos aspectos do caos, contudo de modo matemático afirmando que as Leis fundamentais da natureza eram formuladas tradicionalmente como trajetórias ou funções de ondas. Atualmente, porém, segundo o autor elas são melhor formuladas como uma evolução de probabilidade porque "[...] é preciso recorrer a uma abordagem estatística de base probabilística, [...] pois, ao abandonarmos as trajetórias, deixamos as tranquilas certezas da dinâmica clássica" (2002, p. 37), chegando assim ao seu esquema conceitual: instabilidade, probabilidade e irreversibilidade, ressaltando, assim, a característica de incerteza no comportamento destes sistemas ao longo de sua vida.

Para Prigogine (2002), o caos tem um papel fundamental para descrição da natureza, em qualquer escala (micro, macro e cosmos), sendo este uma nova ordem do sistema, uma consequência de fatores de instabilidade, que introduzem novos aspectos essenciais a ele. De acordo com Carvalho (2012, p. 15) este é um dos aspectos fundamentais de Prigogine, “[...] o caos amplia a noção de lei da natureza e está, diferentemente do que se pensa no senso comum, associado a um novo tipo de ordem". Por exemplo, considerando a evolução das espécies como o sistema em análise, a 
mutação é um elemento necessário para que uma espécie evolua (MORET et al., 2012).

Neste entendimento, o tempo pode ser representado por uma linha, e no seu transcurso serem marcados pontos que representam eventos. Os eventos podem alterar o curso que a linha do tempo vinha seguindo, provocando desdobramentos, modificando o comportamento da trajetória do tempo e gerando instabilidade. A partir desses desdobramentos, estruturas são criadas e podem estabilizar a instabilidade produzida pelo evento, o que irá desenvolver o sistema ou podem também impedir seu desenvolvimento, congelando-o no tempo.

As estruturas chamadas de "estruturas de não-equilíbrio" ou "dissipativas" promovem a evolução do sistema. Prigogine (2002) argumenta que

[...] hoje em dia sabemos que a matéria se comporta de maneira radicalmente diferente em condições de não equilíbrio, ou seja, quando os fenômenos irreversíveis desempenham um papel fundamental. Um dos aspectos mais espetaculares desse novo comportamento é a formação de estruturas de não-equilíbrio (PRIGOGINE, 2002, p. 21).

Desse modo, identificar eventos transcorridos no tempo significa mapear a construção de um sistema em um intervalo de tempo de interesse, entendendo que este tempo transcorrido não poderá ser recuperado em uma posição anterior, nem desconstruir as estruturas criadas pelos eventos (ou seja, é irreversível), mas pode permitir entender os processos ocasionados por eles e o surgimento de novas estruturas, sendo estas de não equilíbrio ou não.

Diante do exposto sobre Sistemas Dinâmicos Instáveis, podem ser identificadas nas Festas de Largo as características levantadas por Nussenzveiog (2003), como por exemplo: (a) sofreram alterações constantes nas suas diferentes edições; (b) possui um conjunto de atores que interagem entre si e com o meio ambiente; (c) as festas são não lineares, cada unidade produz uma resposta aos sinais que recebe; (d) alterações realizadas podem não satisfazer a 
todos os envolvidos nas festas (frustação); (e) o sistema é adaptativo (aprendizado); (f) algumas características das festas são distribuídas ao acaso (aleatoriedade); (g) o sistema se auto organiza de forma espontânea, ordenando-se a partir de um estado desordenado; (h) as festas são um sistema hierárquico (Estado, barraqueiro, população). Além de ser um sistema dentro de outro sistema maior, a cidade.

As Leis que regulamentam as Festas de Largo ao longo de sua existência podem ser interpretadas como eventos que levaram a mudanças históricas, introduzindo aspectos essenciais a elas. Organizaram estruturas dinâmicas instáveis que permitiram o seu bom desenvolvimento ao longo do tempo como, maior segurança; organização dos espaços públicos; possibilidade de atendimento ao maior número de pessoas (com o crescimento do tamanho de algumas festas); criação de serviços públicos de apoio, como coleta de lixo, postos de saúde, etc.

Por outro lado, estes marcos legais também criaram estruturas não dissipativas, que têm levado ao congelamento e eventualmente a morte de determinados aspectos da festa, principalmente no que diz respeito a sua expressão cultural.

Para identificar o impacto no desenvolvimento e mudança das características deste sistema, principalmente no que diz respeito aos aspectos compositivos das barracas, este trabalho apresenta os diferentes marcos regulatórios das Festas de Largo ao longo das 3 últimas décadas.

\section{Materiais e métodos}

Para desenvolver esta narrativa histórica foi realizada uma revisão sistemática de literatura no acervo on-line das Leis do município de Salvador disponibilizadas no banco de dados da Prefeitura Municipal, no sistema LeisMunicipais ${ }^{1}$.

$\mathrm{Na}$ pesquisa, realizada em setembro de 2018, foram buscadas: (a) leis, (b) leis complementares, (c) decretos, (d) decretos

${ }^{1}$ Disponível em: www.https://leismunicipais.com.br/prefeitura/ba/salvador. Acesso em: 10 jan. 2020. 
legislativos, (e) resoluções e, (f) atos vinculados a estas como alterações, regulamentações ou revogações. Foram utilizados como descritores os seguintes termos: "festas populares", "operação festas populares", "barracas tradicionais" e "barracas padronizadas", a partir dos quais foram identificados 144 assuntos relacionados.

A pesquisa sistematizada pelo descritor "barracas tradicionais" e "barracas padronizadas", não encontrou nenhuma norma que já não estivesse vinculada aos outros buscadores, sendo, portanto, os descritores principais desta pesquisa: “Festas populares" e "operação festas populares".

Após o levantamento inicial e a identificação de uma série de Leis relativas aos descritores, foi necessário selecionar as que seriam relevantes ao estudo proposto: a construção de uma narrativa histórica das intervenções municipais (eventos) nas Festas de Largo, com vistas a entender a perda da expressão artística na construção das barracas. Neste sentido, foram utilizados critérios de inclusão e de exclusão para a seleção das Leis levantadas que seriam estudadas detalhadamente.

Diante disto, foram escolhidos como critérios de inclusão: (a) a presença dentro do corpo da Lei dos termos: "festa", "festas populares", "barracas tradicionais", "barracas" e "barracas padronizadas" e que detalhasse assuntos sobre eles; (b) assuntos relacionados com a operacionalização, execução e montagem das festas e barracas; (c) recorte temporal da pesquisa; (d) atos vinculados (mesmo não contendo os descritores escolhidos).

Como critério de exclusão foram adotados: (a) não possuir os termos escolhidos e indicados acima; e, (b) não possuir relevância com o tema das festas e suas barracas de comida e bebida, como por exemplo regulamentos que tratam de aplicação de taxas e multas, de remuneração extra para agentes municipais que trabalham nas festas etc.

Após a realização da pesquisa sistemática os marcos regulatórios foram analisados com o objetivo de identificar sua 
relação (e.g. os impactos, as interferências, os benefícios etc.) no desenvolvimento das barracas ao longo dos anos e as instabilidades geradas por estes eventos.

\section{Resultados}

Como resultado da pesquisa sistemática, e adotando os critérios de inclusão e exclusão, foram encontrados 15 marcos regulatórios (eventos) relevantes ao tema, que foram representados em ordem cronológica na Figura 1, incluindo sua identificação.

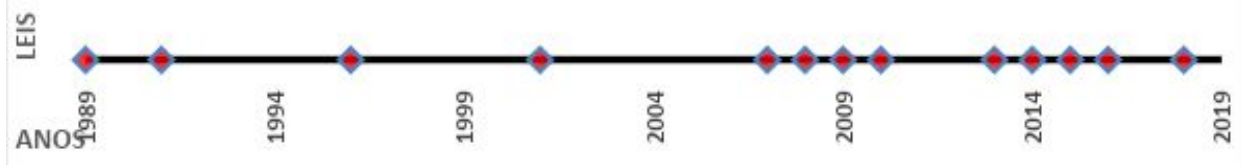

Figura 1: As Leis na linha do tempo Fonte: Autoras, 2019.

A primeira Lei identificada nesta pesquisa é a que cria o Conselho Municipal de Festas Populares, Lei $n^{\circ} 4.009$ de 1989 (SALVADOR, 1989). Este Conselho seria composto por representantes de entidades ligadas diretamente aos Festejos Populares do Município de Salvador, um representante da Prefeitura Municipal e outro indicado pela Câmara de Vereadores, vinculado à Secretaria Municipal de Desenvolvimento Econômico.

Ainda em 1991 esta Lei foi regulamentada pelo Decreto $\mathrm{n}^{\circ}$ 8.418 (SALVADOR, 1991 b), que atribuiu a presidência do Conselho Municipal ao diretor presidente da Empresa de Turismo S.A (EMTURSA, atual SALTUR), deu-lhe como finalidade a de organizar as festas populares do Município, com as seguintes competências: (a) definir o calendário de eventos para a Cidade; (b) estudar, detalhada 
e isoladamente, cada festa, programando as suas realizações; (c) congregar pessoas e entidades com vista a promoção e organização de eventos; e, (d) exercer outras atividades relacionadas com festas populares.

Ainda, constituiu o Conselho pelos seguintes representantes das entidades municipais: SALTUR, Fundação Gregório de Mattos (FGM), Conselho Baiano de Turismo, Câmara de Vereadores, Federação de Culto Afro, Secretaria de Cultura do Estado da Bahia e o Instituto Geográfico e Histórico da Bahia.

A operacionalização das festas passou a ser realizada por uma comissão executiva designada pelo presidente da SALTUR, com participação obrigatória das seguintes entidades: Superintendência de trânsito de Salvador, SETRAM, Superintendência de Manutenção e Conservação da Cidade, SUMAC, Empresa de Limpeza Urbana do Salvador, LIMPURB, Polícia Militar, Companhia de eletricidade do Estado da Bahia, COELBA, Secretaria Municipal de Saúde e Assistência Social, Secretaria de Saúde do Estado da Bahia, podendo haver representantes de outros órgãos ou entidades.

O calendário de eventos para a Cidade do Salvador foi definido pela Lei n 4.390 de 1991 (SALVADOR,1991), que identificou, nesta época, 27 festas ao longo do ano, colocando sob o encargo do Chefe do Poder Executivo Municipal a promoção de meios que viabilizem a sua execução. Este calendário oficial foi se alterando ao longo dos anos, incorporando ou excluindo alguma festa.

A Lei $n^{\circ} 5.175$ de 1996 proíbe a comercialização de bebidas em embalagens de vidro, determinando o uso de embalagens plásticas para venda de alimentos e bebidas. Esta Lei tinha como objetivo gerar maior segurança à população e ao comércio de bebidas durante as festas populares (SALVADOR, 1996 a). O Decreto $n^{\circ} 11.443$ de 1996 que regulamenta esta lei, lista os estabelecimentos que estão nas áreas destinadas às Festas Populares e que devem se ater à Lei (SALVADOR, 1996 b). 
Em 2001, cinco anos após a proibição de embalagens de vidro, a administração pública proíbe também a utilização de mesas e bancos de madeira nas festas populares. Segundo a Lei n. 5.880, “[...] ficam os proprietários de estabelecimentos comerciais, barracas de festas populares e eventos ocasionais, proibidos de utilizarem mesas e bancos de madeira; parágrafo único - As mesas e bancos mencionados "in caput" deste artigo, deverão ser de material plástico" (SALVADOR, 2001, p. 1).

Seis anos mais tarde, em 2007, por meio da Lei $n^{\circ} 7.315$ é criado o Conselho Municipal de Cultura (CMC), vinculado à Secretaria Municipal de Educação e Cultura, que revoga a Lei nº 4.373 de 1991, e autoriza a criação do Conselho Municipal de Cultura como órgão da administração do município, dando também outras providências (SALVADOR, 2007).

O escopo do CMC de 2007 era viabilizar a relação entre a administração municipal e os setores da sociedade civil ligados à cultura, participando da elaboração, da execução e da fiscalização da política cultural da Cidade do Salvador. Dentre suas prerrogativas, competia-lhe estimular a democratização e a descentralização das atividades de produção e difusão culturais no município, procurando fomentar a "[...] cidadania cultural como direito de acesso e fruição dos bens culturais, de produção cultural e de preservação da memória histórica, social, política e artística" (SALVADOR, 2007, p. 6).

No ano seguinte, o município publica o Decreto $n^{\circ} 19.066$ de 2008, sendo este o mais contundente em relação à intervenção do Estado frente ao cenário e à ocupação do espaço público durante as festas. Ele dispõe sobre o exercício de atividades do comércio informal em logradouro público, durante as festas populares de 2008 e 2009 e nele foi encontrada pela primeira vez, neste levantamento sistemático das leis municipais, o termo "barraca padronizada", no seu art. $1^{\circ}$ :

A exploração de atividades de comércio informal em logradouro público, através de equipamentos do tipo barraca padronizada pela Prefeitura Municipal do Salvador, barraca tradicional, 
quermesse e comércio ambulante em geral, durante as festas populares, dependerá de autorização da Secretaria Municipal de Serviços Públicos - SESP, através da Coordenadoria de Licenciamento e Fiscalização de Atividades - CLP (SALVADOR, 2008, p. 8, grifo nosso).

Segundo este Decreto, só será permitida a instalação de qualquer equipamento após a demarcação física das áreas a serem ocupadas e da expedição da autorização por parte dos órgãos competentes. Ainda, deverão ser obedecidos os locais determinados, as datas estabelecidas no calendário oficial e comprovado o pagamento da taxa estipulada de acordo com os tipos e dimensões dos equipamentos e atividades.

Neste Decreto, fica estabelecido também que, para as festas de Nossa Senhora da Conceição, Boa Viagem, Lavagem do Bonfim, e Itapuã, só será permitida a instalação de barraca padronizada pela Secretaria Municipal de Serviços Públicos, a atual SEMOP. Ou seja, 4 das 27 festas indicadas na Lei 4.390 recebem essa imposição.

O parágrafo $2^{\circ}$ deste Decreto determina que as barracas padronizadas só poderão ser montadas, mantidas e desmontadas pela própria SEMOP, diferentemente das barracas nas demais festas: "Os encargos de instalações, montagem, desmontagem e manutenção, são de responsabilidade de cada autorizado, a exceção das barracas e quermesses padronizadas pela PMS/SESP" (SALVADOR, 2008, p. 8).

Em 2009, a municipalidade cria o Estatuto das Festas Populares, Decreto $n^{\circ}$ 20.505. Neste decreto, delega a SALTUR (além das atribuições historicamente dadas a ela relativas às festas e eventos de rua como, organização e articulação multinstitucional municipal) um novo papel, de "[...] inclusive adotar o procedimento necessário à comercialização dos mesmos e elaborar o calendário oficial da Cidade" (SALVADOR, 2009, p. 25), ou seja, foi atribuído oficialmente às festas de rua, populares e tradicionais, valor de mercadoria.

Dessa maneira, ficam estabelecidas neste Decreto, as regras e formas de cobrança do espaço publicitário nas festas. Entende-se 
por “[...] publicidade ou propaganda toda e qualquer forma de propagação de ideias, identificação, marcas, produtos, mercadorias ou serviços por quaisquer meios ou canais que transmitam as mensagens" (SALVADOR, 2009, p. 25). Fica atribuído a SUCOM a obrigação de fiscalizar os engenhos publicitários e à SALTUR a contratação. O Estatuto das Festas Populares regulamenta detalhadamente as atribuições dos órgãos municipais envolvidos nas festas que trabalharão conjuntamente na Central de Licenciamento de Eventos (CLE), posto avançado da Prefeitura Municipal do Salvador.

No ano seguinte, a municipalidade lança novamente uma operação para as festas populares, “Operação festas populares 2010" através do Decreto $\mathrm{n}^{\circ}$ 20.575, reforçando a necessidade de organização capaz de atender a demanda de serviços durante as festas.

É interessante apontar que o então Prefeito destaca a importância da diversidade presente nas festas populares de Salvador, dando o nome de "particularidades" dos festejos populares da cidade no seu amplo aspecto: lúdico, cultural, cívico, social e econômico; aponta o aumento significativo da população flutuante durante estes festejos; sinaliza a complexidade operacional para a coordenação dos eventos e a necessidade de "melhor definir as ações dos diversos órgãos e Entidades da Administração Municipal envolvidos durante as Festas Populares" (SALVADOR, 2010, p. 3). Decreta então a SALTUR como responsável pela coordenação das festas populares.

O Decreto $\mathrm{n}^{\circ} 20.575$ de 2010 regulamenta apenas 8 festas populares da cidade de Salvador: (1) Festa do Réveillon; (2) Festa do Pôr do Sol; (3) Festa da Boa Viagem; (4) Festa da Lavagem do Bonfim; (5) Festa de lemanjá; (6) Festa da Lavagem de Itapoan; (7) Festa de São João; e, (8) Festa de N. Sra. da Conceição da Praia. Vale ressaltar que as festas de Largo listadas neste decreto são as mesmas que possuem a imposição das barracas padronizadas na operação 
anterior (Nossa Senhora da Conceição, Boa Viagem, Lavagem do Bonfim, e Itapuã).

Em agosto de 2013, a Lei ordinária nº 8.455 considera de utilidade pública municipal a Associação dos Barraqueiros de Festas Populares do Estado da Bahia (ABAFEST) (SALVADOR, 2013). Isto representa uma força para a categoria, que passa a possuir uma representatividade reconhecida e oficial. A lei não especifica qual deve ser a participação da associação de barraqueiros para o planejamento e a realização das festas populares de Salvador, mas indica maior participação popular.

Em 2014, o Chefe do Poder Executivo institui o Sistema Municipal de Cultura do Salvador (SMC) por meio da Lei $n^{\circ} 8.551$, revogando a Lei $n^{\circ} 7.315$ de 2007, com a finalidade de formular políticas, campanhas e ações destinadas ao fortalecimento das atividades artístico - culturais em Salvador. Em 2007, os eventos de rua tinham participação no conselho Municipal de Cultura por meio das comissões temáticas, perdendo esta participação com a nova Lei de 2014, que institui o SMC.

Como um dos objetivos específicos desta nova Lei, encontra-se:

[...] promover e estimular as atividades do calendário cultural, constituído tradicionalmente pelas festas religiosas, civis e populares, bem como os festivais, feiras, salões de arte, saraus, música, teatro, dança, circo, cinema, artes visuais, fotografia, design, artesanato e literatura (SALVADOR, 2014, p. 14).

Em maio de 2015, a municipalidade apresenta o Decreto de $n^{\circ} 26.021$ considerando necessário aperfeiçoar a regulamentação do licenciamento e a autorização especial para a realização de eventos temporários no Município. Sendo assim, a realização de eventos em Salvador depende de prévio licenciamento e este pode ser obtido através da CLE. Este decreto considera "evento" a:

[...] realização de shows e toda e qualquer atividade recreativa, social, cultural, educacional, religiosa ou esportiva, ou acontecimento institucional ou promocional, comunitário ou não, previamente planejado com a finalidade de criar conceito e 
estabelecer a imagem de organizações, produtos, serviços, ideias e pessoas, cuja realização tenha caráter temporário, com ou sem venda de ingresso e que ocorram em Imóveis públicos ou privados, logradouros públicos e terrenos vagos e/ ou não edificados (SALVADOR, 2015, p. 4).

O porte dos eventos para efeito de cobrança de taxa e a necessidade de serviços foi classificado neste Decreto como de: (a) Mínimo porte, público estimado de até 500 participantes; (b) Pequeno Porte, com público estimado de 501 a 2.000 pessoas; (c) Médio Porte, com público estimado de 2.001 a 5.000; e, (d) Grande Porte, com público estimado acima de 5.000 pessoas. Excluiu-se deste Decreto o Carnaval por possuir uma legislação específica.

A prefeitura defende que essa central estimula a cadeia de produção do setor de eventos, pois facilita o processo de licenciamento. A CLE já fazia parte das festas populares e se apresentava como um posto avançado da prefeitura, de acordo com o Decreto n² 20.505 de 2009.

A Lei $n^{\circ} 9.069$ de 2016, que dispõe sobre o Plano Diretor de Desenvolvimento Urbano do Município de Salvador (PDDU) e está em vigência, apoia e incentiva a profissionalização das atividades relacionadas à produção das festas. No seu artigo 14 especifica:

As diretrizes para o apoio às atividades industriais, comerciais e de produção de serviços são: [...] III - apoio à economia da cultura, lazer e entretenimento, incentivando e viabilizando a modernização, expansão e implantação de museus, centros culturais e de interpretação e casas de espetáculos, bem como a organização e profissionalização das atividades relacionadas à produção das festas de largo e outros eventos (SALVADOR, 2016, p. 179, grifo nosso).

Em 2018, a prefeitura municipal volta novamente suas atenções ao sistema municipal de cultura e aprova o Regimento do Conselho Municipal de Política Cultural (CMPC) por meio da Lei $n^{\circ}$ 30.230 (SALVADOR, 2018). O CMPC tem por finalidade: (a) assessorar o governo municipal na articulação, deliberação e na formulação e gestão das políticas e dos investimentos públicos na área cultural; (b) estabelecer mecanismos de ação compartilhada com os demais entes federados e a sociedade civil; e, (c) acompanhar e fiscalizar a 
execução da política cultural e do Plano Municipal de Cultura no âmbito do Município do Salvador, sendo levados a cabo pela Coordenação Colegiada.

A Lei de 2018 não trata do Conselho Municipal das Festas Populares que foi criado pela Lei $n^{\circ} 4.009$ de 1989 e continua em vigor, segundo o sítio oficial. Diante disto, fica em aberto se os dois Conselhos funcionariam em paralelo ou conjuntamente ou se apenas o CMPC passaria a funcionar.

A Figura 2 reapresenta os principais marcos da regulamentação identificados na linha do tempo e ilustrados na Figura 1, ressaltando as mudanças mais relevantes que cada um deles trouxe para a configuração das Festas de Largo.

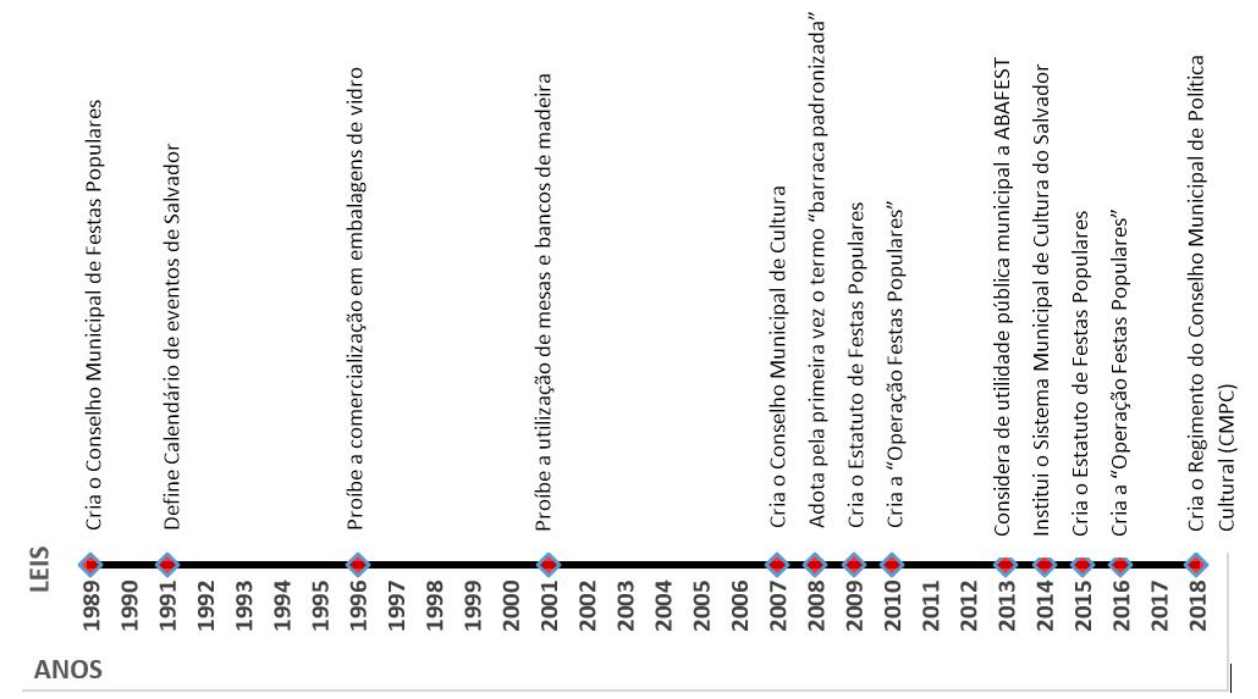

Figura 2: Principais marcos da regulamentação

Fonte: Autoras, 2019.

\section{Discussões sobre as Leis}

Nas Leis analisadas é possível perceber o incentivo à cultura popular (dentre elas as festas) e à cultura em geral. No entanto, em relação à produção e execução das barracas tradicionais e à preservação da ambiência popular nas festas através da sua 
personalização, identifica-se que aspectos culturais foram aos poucos eliminados a partir da introdução de um modelo padronizado de barraca.

A eliminação desse elemento sensível da cultura popular enfraquece na festa seu poder de manifestação cultural e criativo: as Festas de Largo perdem a qualidade de espaço por conta da substituição das antigas barracas tradicionais por um modelo padronizado e em série, assim como a perda de identidade.

As Festas de Largo de Salvador foram, por excelência, espaços sensíveis por muitos anos. Pois são "marcadores" de espaços, onde as memórias, o sentimento de identidade e de pertencimento estão diretamente associados (SANT'ANNA, 2013). Estas festas são acontecimentos temporais que marcam permanentemente os espaços nos quais eles são realizados. "As imagens/paisagens urbanas interferem nos processos contemporâneos de subjetivação e, ainda, na forma como experienciamos os lugares e os territórios da cidade" (CAMPBELL, 2015, p. 32).

As "barracas tradicionais" produzidas em outras épocas traziam consigo elementos artísticos que representavam a expressão e as soluções populares de suas épocas, como mostra a Figura 3. Estas estruturas apresentavam a participação popular na confecção das mesmas, confirmando a afirmação de Carvalho (2016, p. 39): “O carnaval de Salvador é conhecido e reconhecido como o "carnaval participação". Portanto, nas festas de Largo, assim como no Carnaval, notava-se a participação popular. Essa é a singularidade das festas baianas. "Participação" significa facultar a todos o papel de ator, sujeito do espetáculo".

Um dos prazeres visuais (CARVALHO, 2016) das Festas Largo era a composição estética que os bancos faziam ao serem colocados desarmados quando as barracas estavam fechadas (Figura 3-b). O fotógrafo Adenor Gondim e o artista plástico Cesar Romero se 
inspiraram nas composições que surgiam a partir dessa organização para realizar preciosos registros e trabalhos fotográficos.

A Figura 4 apresenta os modelos mais novos das barracas padronizadas, onde pode ser vista a perda da criação de ambiências e personalização destes objetos.

Além das questões estéticas e culturais, a imposição de um modelo de barraca padronizado e estabelecido pelo poder público (i) gera instabilidade para os barraqueiros já que não executam mais suas barracas, (ii) encerra o negócio econômico de venda e aluguel das barracas entre eles, (iii) pois acaba com a "propriedade" das barracas e com o trabalho dos pintores populares.
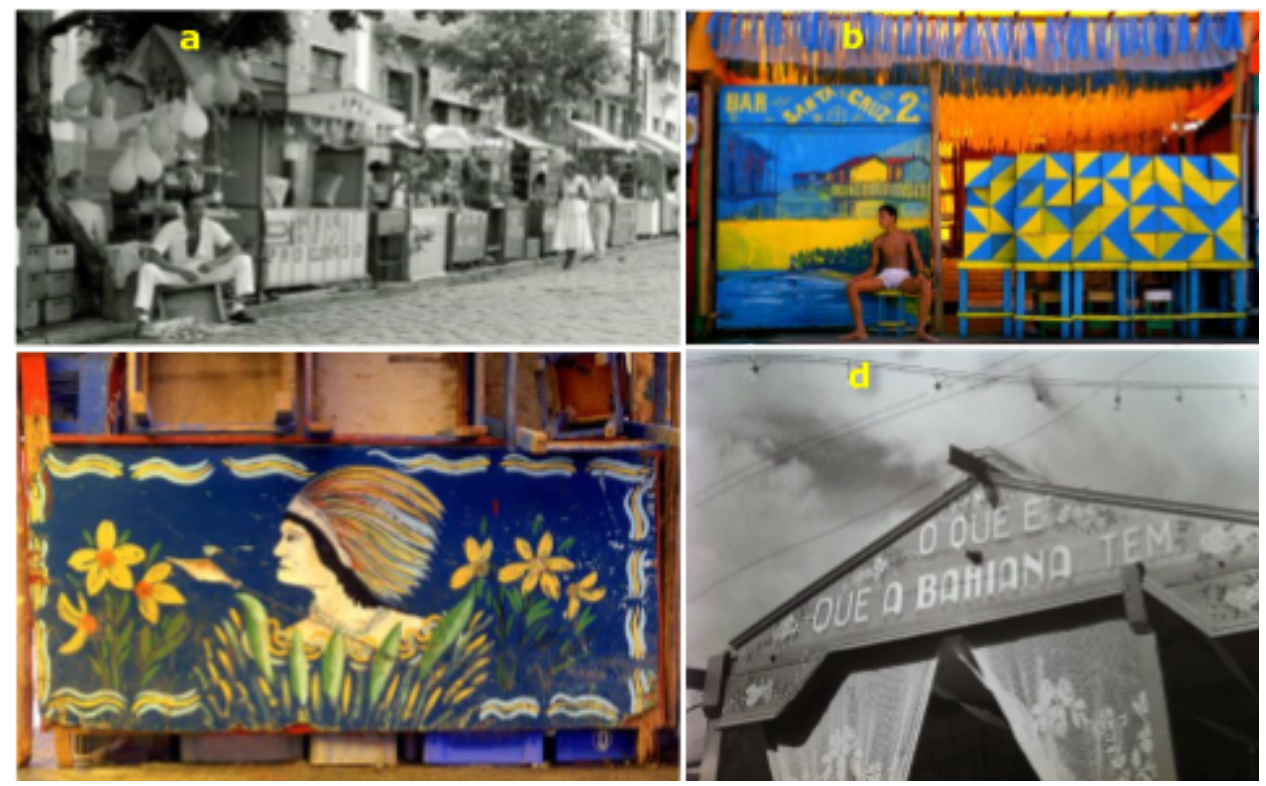

Figura 3: Antigas barracas de Festas de Largo de Salvador

Fonte: (a) Fraga, 1952; (b) e (c) Adenor Gondim, década de 1980; (d) Verger, década de 1950. 


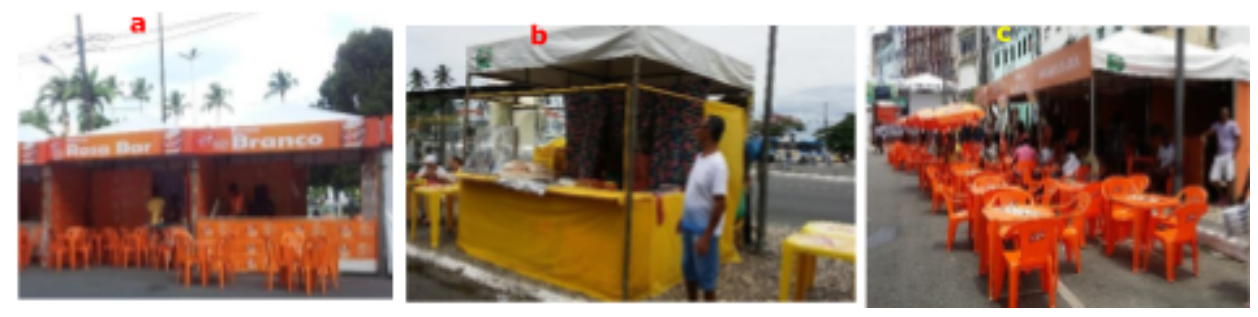

Figura 4: As atuais "barracas tradicionais" das Festas de Largo.

Fonte: (a) Autoras, 2014; (b e c) Autoras, 2017.

A padronização das barracas não cria estruturas de "não equilíbrio", pois tal manifestação do poder municipal anula o aspecto criativo e edificante no qual um sistema instável criaria a partir da interação com meio externo. Este evento estaria mais bem colocado em uma estrutura estática cristalizada, “[...] como os cristais, que uma vez formados podem permanecer isolados e são estruturas "mortas", que não dissipam energia" (PRIGOGINE, 2002, p. 21). Ou seja, esse aspecto faz com o sistema não evolua, como por exemplo, no exemplo dado da evolução das espécies anteriormente.

A Lei n 5.175 de 1996 é outro evento crítico para a atividade econômica dos barraqueiros. Ao proibir o uso de embalagens de vidro nas festas populares, esta Lei gera uma concorrência direta entre os barraqueiros e os vendedores ambulantes, que circulam nas festas com o equipamento tipo "caixa de isopor" e que tem acesso a preços de cervejas em lata diferenciados dos barraqueiros, pois os barraqueiros são obrigados a comprar as cervejas em lata nas cervejarias indicadas pela prefeitura com os preços determinados pelo fornecedor. Os ambulantes estão "livres" para comprar onde for mais conveniente.

Um aspecto importante identificado nesta pesquisa é a constatação que as barracas tradicionais (personalizadas) e padronizadas coexistiram por um período, de acordo com o Decreto $\mathrm{n}^{\circ} 19.066$ de 2008. Atualmente, só existe um tipo de barraca para venda de comidas e bebidas nas Festas de Largo de Salvador, chamada pelo município de "barraca tradicional", porém apesar do nome, esta é o modelo padronizado da prefeitura (Figura 4). 
A partir da pesquisa realizada, percebeu-se objetivos e ritmos diferentes nas ações do Estado frente às festas populares em cada década transcorrida: de 1989 a 2000; de 2001 a 2010 e por fim, de 2011 a 2018, mas o resultado desses eventos foi mesmo, a descaracterização do cenário das Festas de Largo, como mostra a Figura 5.

No primeiro período (1989 a 2000), as Leis estão sob a perspectiva da criação de um conselho municipal de festas populares que oficializa as festas, estabelece as bases da organização municipal (entidades e órgãos que fazem parte da organização, planejamento e execução das festas), e criam proibições de cunho material visando à segurança pública, contudo, o modelo de barraca padronizada já vem sendo utilizado nas festas populares neste período, como mostra a Figura 5.

A partir de 2001 até 2010 houve uma sequência de Leis que fundamentam a regulamentação das festas populares na atualidade. Essa década começa com a criação de proibições de cunho material, passando pela criação do conselho municipal de cultura, pela regulamentação do exercício das atividades do comércio informal no espaço público durante as festas e culmina com o Estatuto das festas populares (Lei que regulamenta toda a festa) criando, por fim, a operação das festas populares que introduz as barracas padronizadas.

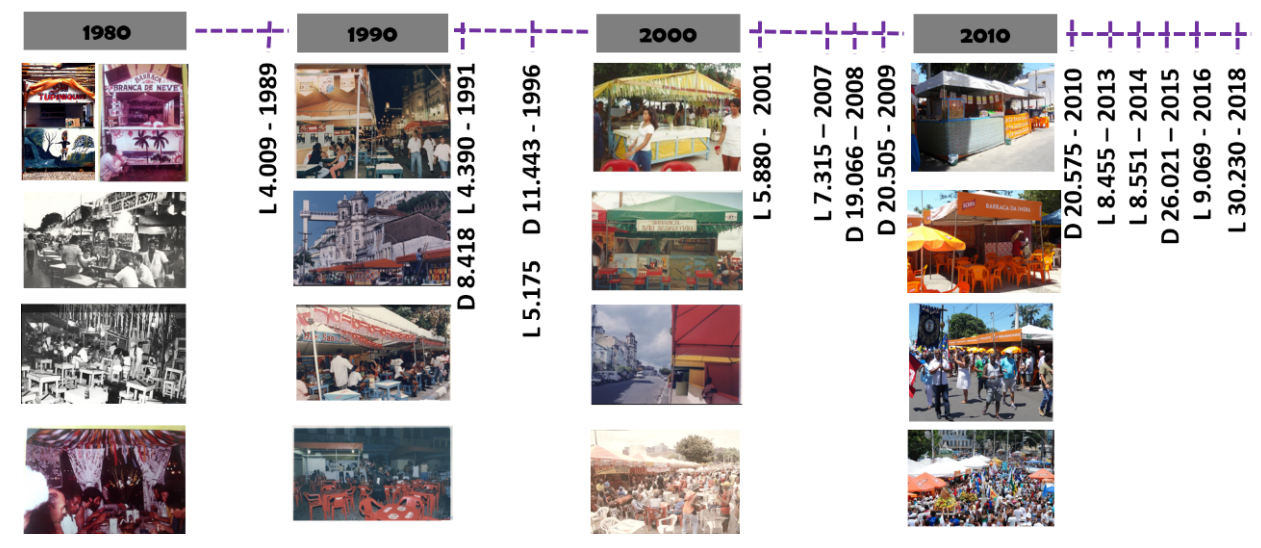

Figura 5: descaracterização do cenário urbano das festas de largo em Salvador 
Fonte: Elaborado pelas autoras, 2019.

Este período está marcado por um intervalo de 5 anos entre a primeira e a segunda Lei (2002 a 2006) seguido por um conjunto de normas sendo promulgadas a cada ano até 2010.

A última década apresenta como marcos importantes o reconhecimento da associação dos barraqueiros, a criação de uma central de licenciamento de eventos, a instituição do sistema municipal de cultura, a inserção das festas no plano diretor e a criação do regimento do conselho municipal de cultura.

\section{Considerações finais}

Dos anos 90 do século passado até os dias atuais, as festas passaram por intervenções municipais importantes que modificaram sua aparência, dinâmica e funcionamento e tais mudanças não podem ser revertidas no tempo. O município de Salvador condicionou as Festas de Largo na cidade tal como se encontram hoje, pois o modelo padronizado de barracas imposto pela prefeitura, a retirada das embalagens de vidro e das cadeiras e mesas de madeira interferiram na aparência e nas relações econômicas entre os atores da festa.

O papel do Estado no campo da promoção das Festas de Largo em Salvador tem sido o de viabilizar as festas, organizar a exploração comercial dos eventos, articular recursos entre as entidades envolvidas (públicas e privadas), ordenar os espaços públicos durante os eventos e fiscalizar o cumprimento das Leis.

Apesar de encontrar nas Leis apoio ao desenvolvimento das manifestações culturais na cidade, percebe-se que o poder público não tem incentivado sua ocorrência nas Festas de Largo no caso das barracas de bebida e comida, e que tais estruturas deveriam ser repensadas pelo viés cultural e não só utilitário/ sanitarista.

No decorrer dos anos, constatou-se tentativas de ordenar e organizar as festas com vista a segurança da população, perdendo-se, contudo, o incentivo à produção cultural como tradicionalmente se apresentava em seu cenário urbano. 
Não se pode mais voltar ao tempo da produção das barracas tradicionais de madeira pintadas, nem é possível anular os eventos gerados durante esses anos pela municipalidade, mas podem ser propostos para o futuro eventos que estejam pautados no resgate ao papel criador e potencializador da cultura sem abrir mão da segurança e da higiene pública nas festas, introduzindo novos aspectos essenciais as barracas de venda de comidas e bebidas. Por exemplo, se for considerada a criação de barracas que conte com a participação dos barraqueiros, e que se utilizem da personalização (assim como em outros aspectos das festas), havendo uma interação entre os atores das festas na construção desse artefato cultural, pode ser possível pensar na geração de estruturas de não-equilíbrio, que mostrem o papel criador fundamental dos fenômenos irreversíveis. 


\section{Referências}

BRANDÃO, C. R. A cultura na rua. Campinas, SP: Papirus, 1989.

CAMPBELL, B. Arte para uma cidade sensível / Art for a sensitive city. São Paulo: Invisíveis Produções, 2015.

CASTRO JUNIOR, L. V. Festa e corpo: as expressões artísticas e culturais nas festas populares baianas. Salvador: EDUFBA, 2014.

CARVALHO, R. F. Temporalidade e historicidade em Ilya Prigogine. Goiânia:

Dissertação (Mestrado em História) - Faculdade de História, Universidade Federal de Goiás, Goiânia, 2012. Disponível em: https://pos.historia.ufg.br/up/113/o/RODRIGO_FRAN\%C3\%87A_CARVALHO.pdf. Acesso em: 19 dez. 2019.

CARVALHO, M. J. A Cidade efêmera do carnaval. Salvador: Editora da UFBA, 2016. MORET, M. A.;PEREIRA, H. B. B.; Galeão, A.C. ; Monteiro, S.L. Evolution of species from Darwin theory: A simple model. Physica. A (Print) v. 391, p. 2803-2806, 2012. NUSSENZVEIOG, M. Complexidade e caos. Rio de Janeiro: Ed UFRJ/ COPEA, 2003. PRIGOGINE, I. As Leis do caos. São Paulo: UNESP, 2002.

SALVADOR. Portal da cidade. Disponível em: https://www.salvadordabahia.com/eventos/festas-populares-e-ensaios-de-verao/. Acesso em: 7 jan. 2020.

SANT'ANNA, M. Fala de Márcia Sant'Anna, Diretora de Patrimônio Imaterial do Iphan, na Inauguração de imóvel restaurado da $7^{a}$ etapa do CHS, 2007. Disponível em: http://www.ipac.ba.gov.br/wp-content/uploads/2011/11/chs.pdf. Acesso em: 04/08/2014.

\section{Marcos normativos}

SALVADOR. Lei $\mathbf{n}^{\circ}$ 4009, de 20 de julho de 1989. Cria o conselho municipal de festas populares. Legislação municipal de Salvador, Salvador, BA, 1989. Disponível em: https://Leismunicipais.com.br/a1/ba/s/Salvador/Lei-ordinaria/1989/401/4009/Lei-ordi naria-n-4009-1989-cria-o-conselho-municipal-de-festas-populares?q=4009. Acesso em: 13 set. 2018.

SALVADOR. Decreto $n^{\circ}$ 8418, de 08 de setembro de 1991. Regulamenta a Lei $n^{\circ}$ 4009/89 e dá outras providências. Legislação municipal de Salvador, Salvador, BA, 1991 b. Disponível em: https://Leismunicipais.com.br/a1/ba/s/Salvador/decreto/1989/842/8418/decreto-n-84 18-1989-regulamenta-a-Lei-n-4009-89-e-da-outras-providencias?q=8418. Acesso em: 13 set. 2018.

SALVADOR. Lei $\mathbf{n}^{\circ}$ 4390, de 06 de novembro de 1991. Define no calendário municipal as festas populares e dispõe sobre sua organização. Legislação municipal de Salvador, Salvador, BA, 1991 a. Disponível em: 
https://Leismunicipais.com.br/a1/ba/s/Salvador/Lei-ordinaria/1991/439/4390/Lei-ordi naria-n-4390-1991-define-no-calendario-municipal-as-festas-populares-e-dispoe-sobr e-sua-organizacao?q=4390. Acesso em: 13 set. 2018.

SALVADOR. Lei $\mathbf{n}^{\circ} \mathbf{5 1 7 5}$, de 27 de junho de 1996. Dispõe sobre a comercialização de produtos em embalagens de vidro em festas populares e dá outras providências. Legislação municipal de Salvador, Salvador, BA, 1996 a. Disponível em: https://Leismunicipais.com.br/a1/ba/s/Salvador/Lei-ordinaria/1996/518/5175/Lei-ordi naria-n-5175-1996-dispoe-sobre-a-comercializacao-de-produtos-em-embalagens-de-v idro-em-festas-populares-e-da-outras-providencias?q=5175. Acesso em: 13 set. 2018. SALVADOR. Decreto $n^{\circ}$ 11443, de 16 de outubro de 1996. Regulamenta a Lei n'5175/96 de 28/06/96, que dispõe sobre a comercialização de produtos em embalagens de vidro em festas populares. Legislação municipal de Salvador, Salvador, BA, 1996 b. Disponível em: https://Leismunicipais.com.br/a1/ba/s/Salvador/decreto/1996/1145/11443/decreto-n11443-1996-regulamenta-a-Lei-n-5175-96-de-28-06-96-que-dispoe-sobre-a-comerciali zacao-de-produtos-em-embalagens-de-vidro-em-festas-populares?q=11443. Acesso em: 13 set. 2018.

SALVADOR. Lei $\mathbf{n}^{\circ} \mathbf{5 8 8 0}$, de 10 de janeiro de 2001. Proíbe a utilização de mesas e bancos de madeiras nas festas populares do município de Salvador e dá outras providências. Legislação municipal de Salvador, Salvador, BA, 2001. Disponível em: https://Leismunicipais.com.br/a1/ba/s/Salvador/Lei-ordinaria/2001/588/5880/Lei-ordi naria-n-5880-2001-proibe-a-utilizacao-de-mesas-e-bancos-de-madeiras-nas-festas-po pulares-do-municipio-de-Salvador-e-da-outras-providencias?q=\%205880. Acesso em: 13 set. 2018.

SALVADOR. Lei $\mathbf{n}^{\mathbf{0}} \mathbf{7 3 1 5}$, de 31 de outubro de 2007. Cria o conselho municipal de cultura, e dá outras providências. Legislação municipal de Salvador, Salvador, BA, 2007. Disponível em:

https://Leismunicipais.com.br/a1/ba/s/Salvador/Lei-ordinaria/2007/732/7315/Lei-ordi naria-n-7315-2007-cria-o-conselho-municipal-de-cultura-e-da-outras-providencias?q= 7315. Acesso em: 13 set. 2018.

SALVADOR. Decreto $n^{\circ}$ 19.066, de 21 de novembro de 2008. Dispõe sobre o exercício de atividades do comércio informal em logradouro público, durante as festas populares de 2008 e 2009 de Salvador, e dá outras providências. Legislação municipal de Salvador, Salvador, BA, 2008. Disponível em:

https://Leismunicipais.com.br/a1/ba/s/Salvador/decreto/2008/1907/19066/decreto-n19066-2008-dispoe-sobre-o-exercicio-de-atividades-do-comercio-informal-em-lograd ouro-publico-durante-as-festas-populares-de-2008-e-2009-de-Salvador-e-da-outras-p rovidencias?q=19.066. Acesso em: 13 set. 2018.

SALVADOR. Decreto $\mathrm{n}^{\circ} \mathbf{2 0 . 5 0 5}$, de 28 de dezembro de 2009. Disciplina o licenciamento e a fiscalização para o desfile de entidades carnavalescas ou 
folclóricas, trios elétricos e congêneres, a instalação e exploração de serviço especial, de camarote, praticável, arquibancada, palcos e similares, o nível de emissão sonora, a exibição de publicidade em geral, o disciplinamento do comércio informal, o sistema de transporte coletivo e de trânsito, a prestação do serviço de saúde, ações da vigilância sanitária, a limpeza urbana e a coleta, o tratamento e o manejo de resíduos sólidos e de qualquer natureza, durante o período de carnaval, de festas populares e de quaisquer eventos que requeiram o exercício do poder de polícia, realizados e incluídos no calendário oficial ou privados na cidade do Salvador. Legislação municipal de Salvador, Salvador, BA, 2009. Disponível em: https://Leismunicipais.com.br/a1/ba/s/Salvador/decreto/2009/2051/20505/decreto-n20505-2009-disciplina-o-licenciamento-e-a-fiscalizacao-para-o-desfile-de-entidades-ca rnavalescas-ou-folcloricas-trios-eletricos-e-congeneres-a-instalacao-e-exploracao-deservico-especial-de-camarote-praticavel-arquibancada-palcos-e-similares-o-nivel-de-e missao-sonora-a-exibicao-de-publicidade-em-geral-o-disciplinamento-do-comercio-in formal-o-sistema-de-transporte-coletivo-e-de-transito-a-prestacao-do-servico-de-sau de-acoes-da-vigilancia-sanitaria-a-limpeza-urbana-e-a-coleta-o-tratamento-e-o-manej o-de-residuos-solidos-e-de-qualquer-natureza-durante-o-periodo-de-carnaval-de-fest as-populares-e-de-quaisquer-eventos-que-requeiram-o-exercicio-do-poder-de-policia -realizados-e-incluidos-no-calendario-oficial-ou-privados-na-cidade-do-Salvador?q=20 .505. Acesso em: 13 set. 2018.

SALVADOR. Decreto $n^{\circ} 20$ 575, de 10 de fevereiro de 2010. Cria a

"operação festas populares 2010", dispõe sobre o regime de trabalho dos órgãos e entidades. Legislação municipal de Salvador, Salvador, BA, 2010. Disponível em:

https://Leismunicipais.com.br/a1/ba/s/Salvador/decreto/2010/2058/20575/decreto-n20575-2010-cria-a-operacao-festas-populares-2010-dispoe-sobre-o-regime-de-trabal ho-dos-orgaos-e-entidades-envolvidos-e-da-outras-providencias?q=20575. Acesso em: 13 set. 2018.

SALVADOR. Lei $\mathbf{n}^{\circ} \mathbf{8 4 5 5}$, de 16 de agosto de 2013. Considera de utilidade pública municipal a associação dos barraqueiros de festas populares do estado da Bahia ABAFEST. Legislação municipal de Salvador, Salvador, BA, 2013. Disponível em: https://Leismunicipais.com.br/a1/ba/s/Salvador/Lei-ordinaria/2013/846/8455/Lei-ordi naria-n-8455-2013-considera-de-utilidade-publica-municipal-a-associacao-dos-barraq ueiros-de-festas-populares-do-estado-da-bahia-abafest?q=8455. Acesso em: 13 set. 2018.

SALVADOR. Lei $\mathbf{n}^{\circ}$ 8551, de 28 de janeiro de 2014. institui o sistema municipal de cultura do Salvador - SMC e dá outras providências. Legislação municipal de Salvador, Salvador, BA, 2014. Disponível em:

https://Leismunicipais.com.br/a1/ba/s/Salvador/Lei-ordinaria/2014/856/8551/Lei-ordi naria-n-8551-2014-institui-o-sistema-municipal-de-cultura-do-Salvador-smc-e-da-outr as-providencias?q=8551. Acesso em: 13 set. 2018. 
SALVADOR. Decreto $\mathbf{n}^{\circ} \mathbf{2 6 . 0 2 1}$ de $\mathbf{0 8}$ de maio de 2015. Dispõe sobre o licenciamento de eventos realizados no município de Salvador, cria a central integrada de licenciamento de eventos e dá outras providências. Legislação municipal de Salvador, Salvador, BA, 2015. Disponível em:

https://Leismunicipais.com.br/a1/ba/s/salvador/decreto/2015/2602/26021/decreto-n26021-2015-dispoe-sobre-o-licenciamento-de-eventos-realizados-no-municipio-de-sal vador-cria-a-central-integrada-de-licenciamento-de-eventos-e-da-outras-providencias . Acesso em: 13 set. 2018.

SALVADOR. Lei $\mathbf{n}^{\circ}$ 9069, de 30 de junho de 2016. Dispõe sobre o Plano Diretor de Desenvolvimento Urbano do Município de Salvador - PDDU 2016 e dá outras providências. Legislação municipal de Salvador, Salvador, BA, 2016. Disponível em: https://Leismunicipais.com.br/a1/ba/s/Salvador/Lei-ordinaria/2016/907/9069/Lei-ordi naria-n-9069-2016-dispoe-sobre-o-plano-diretor-de-desenvolvimento-urbano-do-mu nicipio-de-Salvador-pddu-2016-e-da-outras-providencias?q=9069. Acesso em: 13 set. 2018.

SALVADOR. Lei $\mathbf{n}^{\circ}$ 30230, de 24 de setembro de 2018. Aprova o Regimento do Conselho Municipal de Política Cultural - CMPC. Legislação municipal de Salvador, Salvador, BA, 2018. Disponível em:

https://Leismunicipais.com.br/a1/ba/s/Salvador/decreto/2018/3023/30230/decreto-n30230-2018-aprova-o-regimento-do-conselho-municipal-de-politica-cultural-cmpc?q= 30230. Acesso em: 13 set. 2018.

\section{Resumo}

Este trabalho apresenta uma narrativa histórica sobre as intervenções municipais que regulamentam as festas populares em Salvador - Bahia, especificamente no que diz respeito às suas barracas de comida e bebida. Compreende as Festas de Largo enquanto Sistemas Dinâmicos Instáveis e os marcos regulatórios como eventos que levaram a mudanças em suas configurações, inclusive no desenvolvimento das barracas. Foi realizado um levantamento sistemático de literatura no acervo on-line das Leis do município que identificou 15 marcos regulatórios no período entre 1989 e 2018. Analisando esses marcos, foi possível perceber como o poder público foi padronizando as barracas das festas e reduzindo as possibilidades de personalização e de produção cultural nestes objetos urbanos efêmeros que marcam a paisagem durante os festejos. Este trabalho é parte de uma pesquisa de doutorado em andamento que tem por objetivo principal potencializar o resgate da produção cultural e 
DOI:10.20396/urbana.v11i3.8656274

artística das barracas de venda de comida e bebida em Festas de Largo por meio de novas tecnologias de fabricação digital, adotando o conceito de personalização em massa. A maior contribuição deste trabalho se dá pela sistematização e análise da história das barracas, entendendo e ressaltando a importância dos marcos legais no desenvolvimento destes artefatos na atualidade, assim como a relação destes com os valores culturais desses equipamentos efêmeros.

Palavras-chave: Cenário de Festa de Largo. Estruturas efêmeras. Barracas de comida e bebida. Levantamento sistemático de literatura. Sistemas dinâmicos instáveis.

\section{Abstract}

This paper presents a historical narrative about the municipal interventions that regulate the "Festas de Largo" in Salvador - Bahia, especially with regard to their food and drink tents. This research understands the "Festas de Largo" as unstable dynamic systems and regulatory frameworks as events that led to changes in their configuration, including the development of tents. A systematic literature survey was carried out in the online data of the Municipal Laws that identified 15 regulatory marks in the period between 1989 and 2018. Analyzing these regulatory marks, it was possible to see how the government was standardizing the party tents and reducing the possibilities of personalization and cultural production in these ephemeral urban objects that mark the landscape during the festivities. By analyzing its history, it is possible to propose changes in order to recover cultural values that have been lost over the years. This work is an initial part of a doctoral research that aims to potentialize the recovery of the cultural and artistic production of food and beverage tents in "Festas de Largo", using new digital fabrication technologies, especially the concept of mass personalization. Its major contribution is the systematization and analysis of the history of the tents, understanding and stressing the importance of legal frameworks in the development of these artifacts.

Keywords: Scenarios of "Festas de Largo". Ephemeral structures. Food and drink tents. Systematic literature survey. Unstable dinamic systems.

\section{Resumen}

Este artículo presenta una narración histórica sobre las intervenciones municipales que regulan las fiestas populares en Salvador - Bahía, especialmente con respecto a sus puestos de comida y bebida. Esta investigación entiende las fiestas populares como sistemas dinámicos inestables y 
DOI:10.20396/urbana.v11i3.8656274

los marcos regulatorios como eventos que llevaron a cambios en su configuración, incluido el desarrollo de los qioscos. Se realizó una encuesta bibliográfica sistemática en la colección en línea de las Leyes Municipales que identificaron 15 puntos de referencia regulatorios en el período comprendido entre 1989 y 2018. Al analizar estos puntos de referencia, fue posible ver cómo el gobierno estaba estandarizando los quioscos de fiestas y reduciendo las posibilidades de personalización y producción cultural en estos efímeros objetos urbanos que marcan el paisaje durante las festividades. Al analizar su historia, es posible proponer cambios para recuperar los valores culturales que se han perdido a lo largo de los años. Este trabajo es una parte inicial de una investigación doctoral que tiene como objetivo mejorar la recuperación de la producción cultural y artística de puestos de comida y bebida en fiestas populares, utilizando nuevas tecnologías de fabricación digital, especialmente el concepto de personalización en masa. Su mayor contribución se realiza mediante la sistematización y el análisis de la historia de los puestos de comida e bebida, entendiendo y destacando la importancia de los marcos legales en el desarrollo de estos artefactos.

Palabras clave: Estructuras efímeras. Quioscos de comida y bebida. Estudio sistemático de literatura. Sistemas dinámicos inestables. 